\title{
KEIKUTSERTAAN PROGRAM KESEHATAN LANSIA DITINJAU DARI BIAYA, KEPUASAN PELAYANAN DAN HARAPAN PASIEN DI PUSKESMAS NANGGULAN KABUPATEN KULON PROGO
}

\author{
Dina Fitriana Rosyada, Savitri Citra Budi \\ Prodi Diploma Rekam Medis, Sekolah Vokasi Universitas Gadjah Mada
ELDERLY PROGRAMME INVOLVEMENT REVIEWED FROM COST, SERVICE NANGGULAN KULON PROGO DISTRICT \\ SATISFACTORY AND PATIENT EXPECTATIONS IN PUBLIC HEALTH CENTER
}

\begin{abstract}
Background: One of the efforts to improve social welfare for elderly is to provide health services. The coverage of the utilization of elderly patient care at Nanggulan public health center is still low. The low coverage is certainly caused by the fundamental things related to the selection of health care facilities such as the existence of cost considerations, patient expectations and satisfaction on quality health service facilities. The objectives of this research is to analyze the influence of the fundamental reasons for the selection of health service facilities at Nanggulan public health center towards participation in the elderly program.

Methods: The type of research is observational analytic research with cross sectional study design. The sample size of this study is 50 elderly. The sample size is calculated using random sampling technique. The dependent variable of the research is the participation of the lansia elderly program and the independent variables of the study are cost consideration, patient expectation and satisfaction of service quality at Nanggulan public health center.

Results: The analysis statistic used logistic regresion, the variables that influence the utilization of elderly health service program at Nanggulan Community Health Center are the variable of patient satisfaction.

Conclusion: The elderly choose Nanggulan public health center used health but their participation do not affect in elderly program because of the access factor factor or the distance of the house with Nanggulan Health Center involvement of elderly programme was influenced by service satisfaction.
\end{abstract}

Keywords: Elderly program participation, elderly service usage, improvement of elderly welfare.

\begin{abstract}
ABSTRAK
Latar Belakang: Salah satu upaya Peningkatan Kesejahteraan Sosial bagi Lanjut Usia adalah dengan memberikan pelayanan kesehatan. Cakupan pemanfaatan pelayanan pasien bagi lanjut usia di Puskesmas Nanggulan tergolong masih rendah. Rendahnya cakupan tersebut tentunya disebabkan oleh hal yang mendasar berkenaan dengan pemilihan sarana pelayanan kesehatan seperti adanya pertimbangan biaya, harapan pasien dan kepuasan pada kualitas pelayanan sarana pelayanan kesehatan. Tujuan dari penelitian ini adalah menganalisis pengaruh alasan pendasaran pemilihan sarana pelayanan kesehatan di Puskesmas Nanggulan terhadap keikutsertaan dalam program lansia.

Metode: Jenis penelitian adalah penelitian analitik observasional dengan desain penelitian cross sectional. Besar sampel penelitian ini ada 50 lansia. Besar sampel tersebut dihitung menggunakan rumusan teknik random sampling. Variabel dependen penelitian adalah keikutsertaan lansia pada program lansia dan variabel independen penelitian adalah pertimbangan biaya, harapan pasien dan kepuasan kualitas pelayanan di Puskesmas Nanggulan. Analisis Statistik menggunakan uji regresi logistik.

Hasil Penelitian: Analisis statistik menggunakan uji logistik regresi variabel yang mempengaruhi pemanfaatan pelayanan program kesehatan lansia di Puskesmas Nanggulan adalah variabel kepuasan pasien. Kesimpulan: Lansia memilih Puskesmas Nanggulan sebagai tempat pemeriksaan kesehatan namun meski demikian tidak langsung berpengaruh terhadap keikutsertaan mereka pada program lansia karena adanya faktor akses atau jarak rumah dengan Puskesmas Nanggulan. Keikutsertaan program lansia lebih dipengaruhi oleh adanya kepuasan pelayanan.
\end{abstract}

Kata Kunci: Program kesehatan lansia, pemanfaatan pelayanan, pasien, lanjut usia, peningkatan kesejahteraan lansia.

Alamat Koresponding: Dina Fitriana Rosyada, Prodi Diploma Rekam Medis, Sekolah Vokasi Universitas Gadjah Mada, Gedung SV UGM, Sekip Unit 1, Catur Tunggal, Depok, Caturtunggal, Sleman, Kabupaten Sleman, Daerah Istimewa Yogyakarta 55281, email : dinafitriana.r@ugm.ac.id 


\section{PENDAHULUAN}

Permasalahan cukupan pelayanan kesehatan puskesmas baik berupa unit kesehatan perorangan dan unit kesehatan masyarakat bagi pasien lanjut usia di Puskesmas Nanggulan masih rendah. Pelayanan kesehatan dimaksudkan untuk memelihara dan meningkatkan derajat kesehatan dan kemampuan lanjut usia agar kondisi fisik, mental, dan sosialnya dapat berfungsi secara wajar. ${ }^{1}$ Kesehatan Lanjut Usia atau Lansia adalah program pelayanan kesehatan usia lanjut atau upaya kesehatan khusus yang dilaksanakan oleh tenaga kesehatan.

Sensus penduduk tahun 2010 menunjukkan bahwa Indonesia termasuk lima besar negara dengan jumlah penduduk lanjut usia terbanyak di dunia, yang mencapai 18,1 juta jiwa atau 7,6 persen dari total penduduk. Badan Pusat Statistik (2013) memproyeksikan, jumlah penduduk lanjut usia (60+) diperkirakan akan meningkat menjadi 27,1 juta jiwa pada tahun 2020, menjadi 33,7 juta jiwa pada tahun 2025 dan 48,2 juta jiwa tahun 2035. ${ }^{2}$ Perhatian pemerintah terhadap keberadaan lanjut usia ini cukup besar, yang diawali pada tahun 1996 dengan ditetapkannya tanggal 29 Mei yang diperingati setiap tahun sebagai Hari Lanjut Usia. Di bidang kesehatan, Undang-Undang Nomor 36 Tahun 2009 tentang Kesehatan menyebutkan bahwa upaya untuk meningkatkan dan memelihara kesehatan masyarakat dilaksanakan berdasarkan prinsip non diskriminatif, partisipatif dan berkelanjutan. Upaya pemeliharaan kesehatan bagi lanjut usia ditujukan untuk menjaga agar para lanjut usia tetap sehat, mandiri, aktif dan produktif secara sosial dan ekonomi sehingga untuk mewujudkan hal tersebut pemerintah berkewajiban untuk menjamin ketersediaan fasilitas pelayanan kesehatan dan memfasilitasi pengembangan kelompok lanjut usia. $^{3}$

Puskesmas dengan dukungan peran serta aktif masyarakat dalam rangka meningkatkan derajat kesehatan masyarakat usia lanjut. Kemenkes (2015) tentang Standar Pelayanan Minimal di bidang kesehatan di provinsi dan kabupaten/kota menyebutkan bahwa pemerintah daerah kabupaten/kota wajib memberikan skrining sesuai standar pada warga usia 60 tahun keatas yang membutuhkan pelayanan skrining kesehatan. ${ }^{4}$ Tujuan penelitian ini adalah menganalisis pengaruh pendasaran pemilihan sarana pelayanan kesehatan terhadap keikutsertaan dalam program lansia di Puskesmas Nanggulan Kabupaten Kulon Progo.

\section{METODE}

Jenis penelitian adalah penelitian analitik. Desain penelitian yang digunakan adalah observational yaitu studi yang hanya akan melaksanakan pengamatan tanpa intervensi. ${ }^{5}$ Berdasarkan waktunya, penelitian ini merupakan cross sectional karena pengukuran variabelnya dilakukan dalam satu waktu yang sama. ${ }^{6,7,8}$ Populasi dalam penelitian ini adalah seluruh lansia dengan kriteria inklusinya adalah orang yang telah mencapai usia 60 tahun ke atas di wilayah kerja Puskesmas Nanggulan Kulon Progo Yogyakarta. Namun dikarenakan kemungkinan ada yang belum bisa dimintai informasi, maka bisa diwakilkan pada anaknya atau keluarga terkait. Kriteria eksklusi dalam penelitian ini adalah lansia dibawah usia 60 tahun.

Besar sampel dihitung dengan teknik perhitungan random sampling, yakni pengambilan subyek secara acak. ${ }^{9}$ Variabel dalam penelitian ini adalah pendidikan, pendapatan, keikutsertaan dalam program lansia, pertimbangan biaya, kepuasan pelayanan dan harapan pasien lansia. Besar sampel responden dalam penelitian ini adalah 50 responden lansia. Dimana besar sampel tersebut dari populasi kunjungan lansia ratarata per bulan di Puskesmas Nanggulan. Ratarata jumlah lansia yang berkunjung dan 
menggunakan pelayanan Puskesmas per bulan adalah 189 lansia. Data penelitian dianalisis secara univariat, bivariat dan multivariat menggunakan uji regresi logistik. Instrumen yang digunakan untuk penelitian ini adalah lembar kuesioner untuk mendapatkan data primer dari responden dan peralatan dokumentasi untuk mendokumentasi kegiatan pengambilan data.

\section{HASIL PENELITIAN}

Puskesmas Nanggulan merupakan puskesmas rawat jalan yang terletak di Desa Wijimulyo, Nanggulan, Kulon Progo. Wilayah kerja yang menjadi tanggung jawab tugas pelayanannya meliputi 6 desa dengan 61 dusun. Kecamatan Nanggulan merupakan salah satu Kecamatan yang ada di Kabupaten Kulon Progo bagian utara. Batas-batas wilayah kecamatan sebelah utara Kecamatan Kalibawang, sebelah timur Kabupaten Sleman
(Sungai Progo), sebelah selatan Kecamatan Sentolo dan sebelah barat Kecamatan Girimulyo. $^{10}$

Luas wilayah Kecamatan Nanggulan 3.960,67 Ha terdiri dari sawah 1.495,85 Ha, pekarangan $674,56 \mathrm{Ha}$, tegalan $15,71 \mathrm{Ha}$, ladang 885,5 Ha, lain-lain 889,05 Ha. Kecamatan Nanggulan terdiri 6 desa yaitu Desa Wijimulyo, Jatisarono, Kembang, Tanjungharjo, Banyuroto dan Desa Donomulyo, dengan jumlah dusun 61 dusun, Rukun Warga (RW) 128 buah, Rukun Tetangga (RT) 385 buah, dengan jumlah penduduk jiwa terdiri dari laki-laki jiwa dan perempuan jiwa sedangkan jumlah kepala keluarga 9.335. ${ }^{11}$ Variabel yang digunakan untuk mengidentifikasi karakteristik responden adalah umur, jenis kelamin, tingkat pendidikan dan pendapatan. Hasil analisis karakteristik responden disajikan dalam Tabel 1.

Tabel 1.

Karakteristik Responden Lansia di Puskesmas Nanggulan Kabupaten Kulon Progo

\begin{tabular}{lrc}
\hline \multicolumn{1}{c}{ Karakteristik Responden } & $\begin{array}{c}\text { Jumlah } \\
\text { (orang) }\end{array}$ & $\begin{array}{c}\text { Persentase } \\
(\%)\end{array}$ \\
\hline Jenis kelamin & & \\
Laki-laki & 20 & 40 \\
Perempuan & 30 & 60 \\
Umur & & \\
60 - 65 tahun & 25 & 50 \\
66 - 70 tahun & 12 & 24 \\
71 - 75 tahun & 10 & 20 \\
76 - 80 tahun & 3 & 6 \\
Pendidikan & & \\
SD & 24 & 48 \\
SMP & 12 & 24 \\
SMA/SMK & 10 & 20 \\
Perguruan Tinggi & 4 & 8 \\
Pendapatan (Per Bulan) & & \\
<Rp 500.000 & 11 & 22 \\
Rp 500.000 - Rp 1.000.000 & 25 & 50 \\
>Rp 1.000.000-Rp 1.500.000 & 9 & 18 \\
>Rp 1.500.000 & 5 & 10 \\
\hline
\end{tabular}

Berdasarkan tabel 1 diketahui bahwa responden dalam penelitian ini mayoritas perempuan sebesar $60 \%$ sedangkan laki-laki sebesar 40\%. Berdasarkan karakteristik umur responden, mayoritas responden berumur $60-$ 65 tahun yakni sebesar 50\%, sedangkan responden dengan umur 66 - 70 tahun ada $24 \%$, responden dengan umur $71-75$ tahun ada $20 \%$. Hanya ada $6 \%$ responden yang tergolong dalam umur $76-80$ tahun. Berdasarkan hasil analisis tingkat pendidikan diketahui bahwa semua responden pernah 
mengenyam pendidikan formal. Sebagian besar berpendidikan Sekolah Dasar (SD) yakni sebesar $48 \%$. Pada responden yang memiliki pendidikan terakhir Sekolah Menengah Pertama (SMP) ada 24\% sedangkan pada responden yang memiliki pendidikan terakhir Sekolah Menengah Atas/Sekolah Menengah Kejuruan (SMA/SMK) sebesar 20\%. Hanya 8\% responden yang memiliki pendidikan terakhir di Perguruan Tinggi (PT). Berdasarkan hasil analisis tingkat pendapatan diketahui bahwa mayoritas pendapatan per bulan responden adalah Rp 500.000,- sampai Rp 1.000.000,- sebesar 50\% responden. Responden yang memiliki pendapatan per bulan $<\mathrm{Rp} 500.000$,sebesar $22 \%$ sedangkan responden dengan pendapatan per bulan sebesar $>$ Rp 1.000.000,sampai Rp 1.500.000,0 sebanyak 18\%. Hanya ada $10 \%$ responden yang memiliki pendapatan per bulan $>\operatorname{Rp} 1.500 .000,-$.

Variabel terikat dalam penelitian ini adalah keikutsertaan pasien dalam program lansia di Puskesmas Nanggulan Kabupaten Kulon Progo Yogyakarta. Hasil dari pengambilan data keikutsertaan pasien dalam program lansia disajikan dalam gambar diagram sebagai berikut.

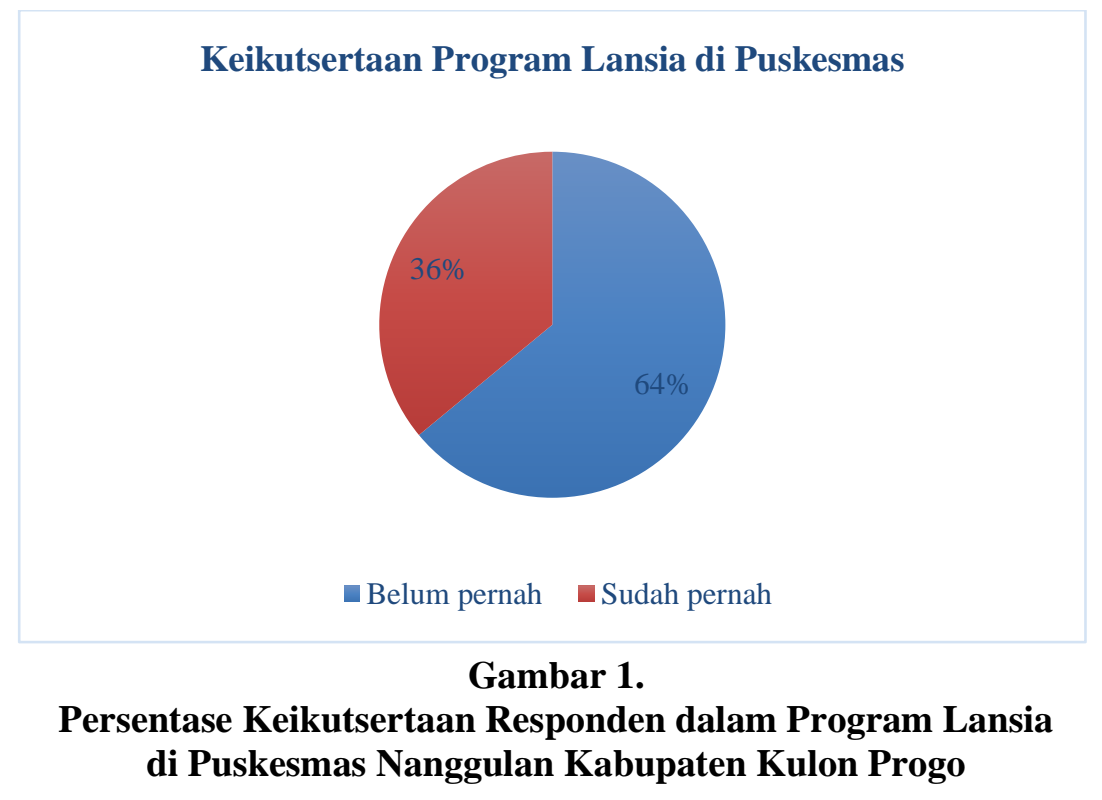

Berdasarkan gambar 1 diketahui bahwa responden lansia yang belum pernah mengikuti program lansia di Puskesmas Nanggulan Kabupaten Kulon Progo Yogyakarta adalah sebanyak 64\%. Program lansia yang dimaksudkan di sini adalah meliputi senam lansia, pemberian makanan tambahan pada lansia, cek rutin kesehatan lansia berupa tes kadar gula dalam darah, cek kadar kolesterol, asam usat dan pemeriksaan penyakit dini lansia. Hanya ada sebanyak $34 \%$ responden lansia yang sudah pernah mengikuti program lansia di Puskesmas tersebut.

Pada penelitian ini digunakan variabel bebas yaitu adanya pertimbangan biaya, harapan pasien lansia dan kepuasan pasien terhadap pelayanan puskesmas. Berikut ini merupakan hasil persentase variabel bebas dalam penelitian. 


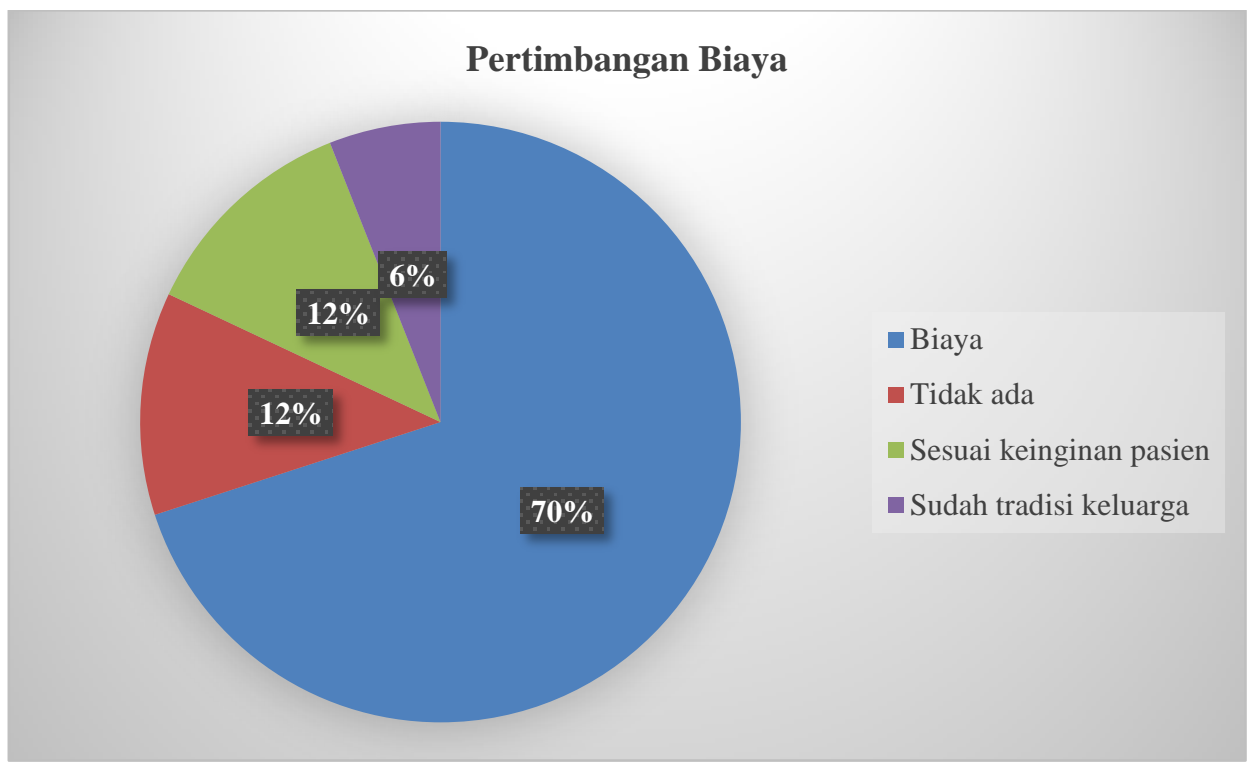

Gambar 2.

Pertimbangan Biaya

Berdasarkan hasil penelitian diketahui responden yang memilih alasan pertimbangan biaya ada sebesar $70 \%$, sedangkan selainnya dengan tidak mempertimbangkan alasan khusus, sesuai keinginan dan kebiasaan tradisi keluarga.

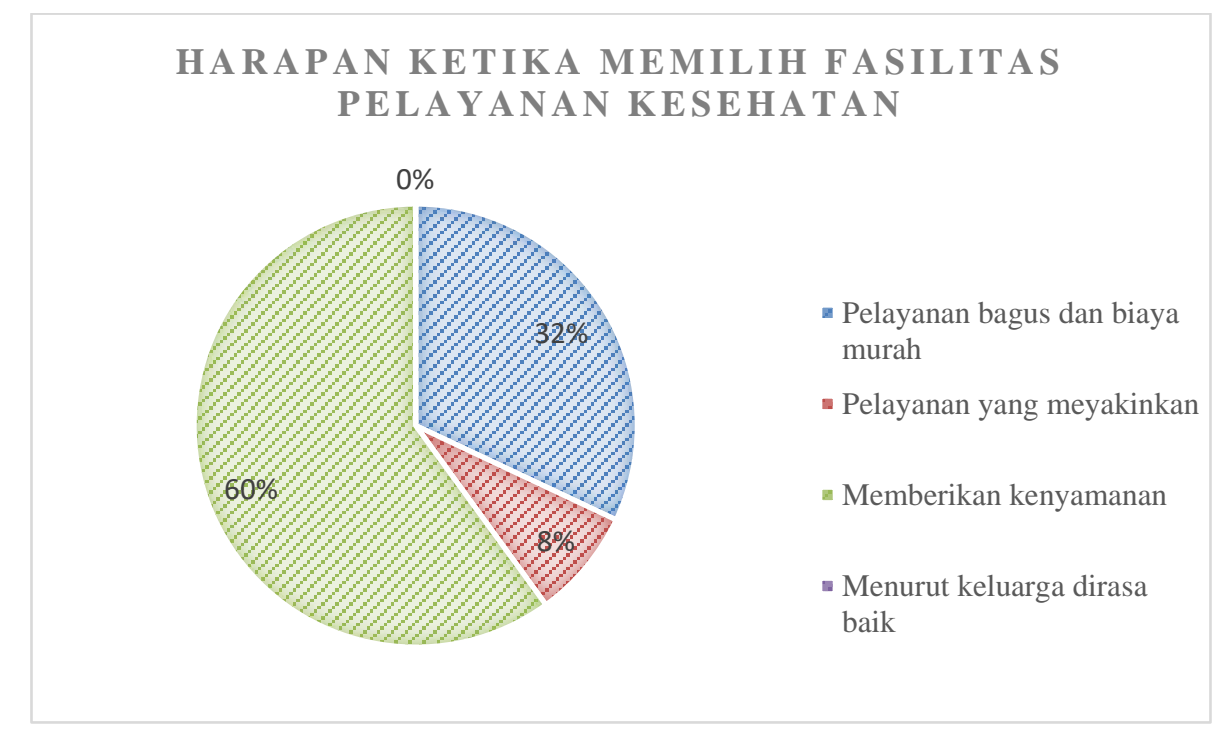

\section{Gambar 3.}

\section{Diagram Persentase Harapan Ketika Memilih Fasilitas Pelayanan Kesehatan}

Berdasarkan hasil penelitian diperoleh harapan dalam memilih tempat untuk memeriksakan kondisi kesehatan lansia adalah mayoritas menjawab $\mathrm{C}$ yaitu mendapatkan pelayanan yang dapat memberikan kenyamanan, ketenangan dan menyenangkan hati. Sebesar 32\% responden yang memilih jawaban A dimana harapannya adalah mendapatkan pelayanan yang bagus dengan biaya relatif murah. Hanya $8 \%$ responden yang memilih jawaban B yaitu dengan harapan mendapatkan pelayanan yang sesuai dengan keyakinan. Tidak ada responden yang memilih jawaban D yakni dengan harapan mendapatkan pelayanan yang menurut keluarga adalah dirasa baik. 


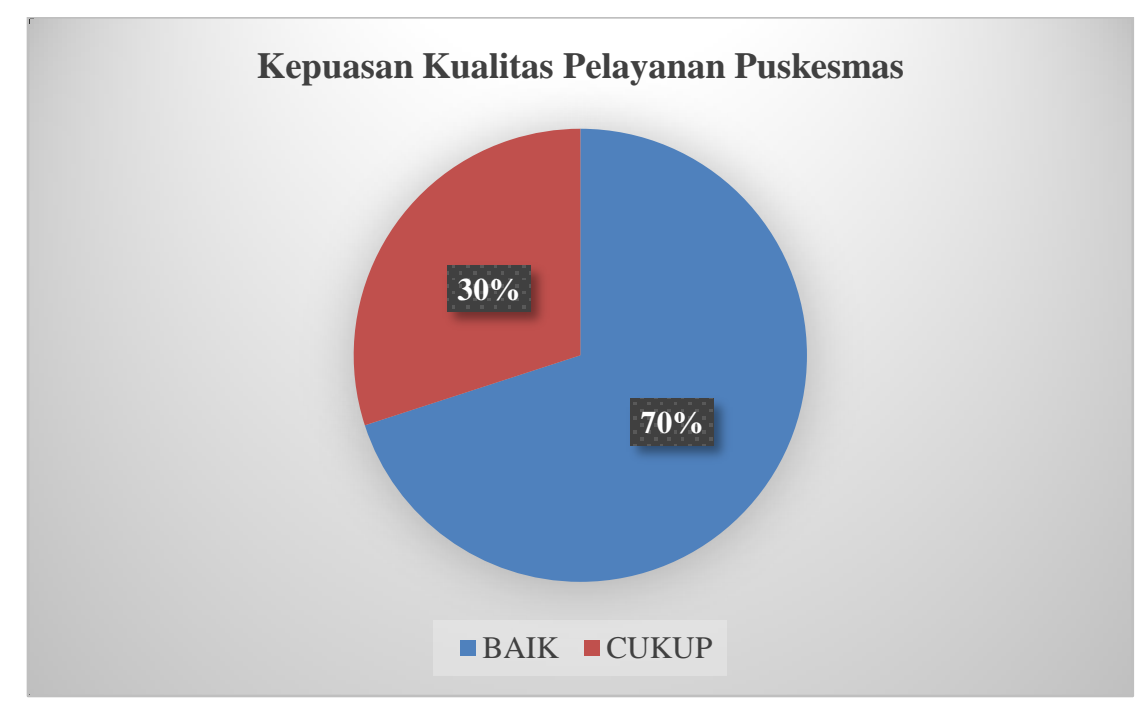

\section{Gambar 4. \\ Diagram Persentase Kepuasan Kualitas Pelayanan Puskesmas Nanggulan Kabupaten Kulon Progo}

Berdasarkan hasil penelitian mengenai pelayanan puskesmas diperoleh mayoritas responden menyatakan baik yakni sebesar
$70 \%$. Sebesar $30 \%$ responden yang menyatakan pelayanan Puskesmas cukup baik

Tabel 2.

Hubungan antara Pertimbangan Biaya, Harapan Ketika Memilih Fasilitas Pelayanan Kesehatan dan Kepuasan Kualitas Pelayanan dengan Keikutsertaan Program Lansia

\begin{tabular}{lccc}
\hline \multicolumn{1}{c}{ Variabel } & Koefisien & P Value & Ket \\
\hline Pertimbangan Biaya & 0,707 & 0,000 & Sig \\
Harapan ketika memilih fasilitas pelayanan kesehatan & - & 1 & - \\
Kepuasan Kualitas Pelayanan & 0,526 & 0,006 & $\mathrm{Sig}$ \\
\hline
\end{tabular}

Berdasarkan hasil analisis hubungan diperoleh bahwa nilai $\mathrm{P}$ untuk variable pertimbangan biaya adalah sebesar 0,000 atau nilai $P<\alpha \quad(\alpha=0,05)$. Dimana hasil ini menunjukkan arti bahwa ada hubungan antara keiutsertaan lansia pada program lansia di Puskesmas Nanggulan. Pada variabel kepuasan kualitas pelayanan puskesmas juga diperoleh hasil yang signifikan, yaitu dengan $\mathrm{P}<$ dari $\alpha$. Dimana menunjukkan bahwa variabel kepuasan pelayanan puskesmas ada hubungan dengan keikutsertaan lansia pada program lansia. Pada variable harapan ketika memilih fasilitas pelayanan kesehatan diperoleh nilai $\mathrm{P}$ sebesar 1 dimana nilai tersebut $>$ dari $\alpha \quad(\alpha=0,05)$, sehingga dinyatakan tidak ada hubungan pada variabel harapan memilih fasyankes dengan keikutsertaan program lansia di Puskesmas Nanggulan Kulon Progo.

Tabel 3.

Pengaruh Pertimbangan Biaya dan Kepuasan Kualitas Pelayanan terhadap Keikutsertaan Program Lansia

\begin{tabular}{lll}
\hline \multicolumn{1}{c}{ Variabel } & P value & Keterangan \\
\hline Pertimbangan Biaya & 0,070 & - \\
\hline Kepuasan kualitas pelayanan & 0,001 & Sig. \\
\hline
\end{tabular}

Hasil analisis multivariate dengan uji statistik regresi logistik menunjukkan bahwa keikutsertaan program lansia lebih dipengaruhi oleh adanya kepuasan pelayanan puskesmas yang telah diterima pengguna 
(lansia) yang sudah pernah berobat di puskesmas tersebut. Hasil tersebut didukung dengan adanya nilai $\mathrm{P}$ value 0,001 yang mana $<\alpha \quad 0,05$ dimana menunjukkan adanya signifikansi pengaruh. Dalam hal kepuasan pelayanan Puskesmas, responden mengemukakan pelayanan yang diberikan pihak Puskesmas sudah baik, dengan petugas yang ramah termasuk dokter yang ramah kepada pasien. Hal tersebut didukung Puskesmas Nanggulan menerapkan adanya program santun lansia, dimana lansia yang berobat ataupun periksa kesehatan ditangani dengan ramah oleh petugas Puskesmas Nanggulan.

\section{PEMBAHASAN}

Karakteristik responden dalam penelitian ini berdasarkan jenis kelamin mayoritas responden adalah perempuan, hal ini sejalan dengan pada penelitian terkait faktor-faktor mempengaruhi lansia tidak mengikuti Posyandu lansia di Jombang tahun 2013 dan penelitian faktor yang mempengaruhi minat lansia mengunjungi Posyandu. ${ }^{12,13}$ Dari hasil penelitian menunjukkan bahwa responden lansia memilih pertimbangan biaya sebagai pertimbangan memillih sarana pelayanan kesehatan namun bukan berarti pertimbangan biaya adalah pertimbangan yang utama, karena hal tersebut didukung pula dengan kepuasan pelayanan puskesmas. Hal tersebut sejalan dengan penelitian yang menyatakan bahwa adanya respon lanjut usia terhadap biaya kesehatan merasa puas dengan jaminan kesehatan masyarakat. ${ }^{14}$

Namun disisi lain dalam pemanfaatan pelayanan program lansia pengguna layanan yaitu masyarakat lansia di Nanggulan hanya menggunakannya ketika sakit saja, tidak untuk pemeriksaan kesehatan rutin, dimana idealnya lansia memeriksakan kesehatannya sebulan sekali ke puskesmas untuk kontrol kondisi kesehatan. Lebih lanjut mengikuti program lansia yang diadakan pihak
Puskesmas Nanggulan yaitu senam sehat lansia dan cek kesehatan lansia. Hasil dari penelitian menunjukkan tidak adanya pengaruh variabel pertimbangan biaya dan harapan responden dengan keikutsertaan program lansia di Puskesmas Nanggulan. Dari alasan yang dikemukakan responden dalam wawancara menggunakan lembar kuesioner terkait kendala tidak rutin ke puskesmas untuk ikut serta dalam program lansia adalah karena faktor jarak rumah dengan puskesmas, dan ketidaktahuan informasi adanya program lansia dari Puskesmas Nanggulan. Hal ini didukung dengan penelitian yang menyatakan bahwa faktor yang mempengaruhi kunjungan lansia ke posyandu yaitu didukung keluarga yang baik, sikap yang baik, pengetahuan baik, asumsi lansia yang tidak bekerja, akses yang baik dan adanya dukungan masyarakat. ${ }^{15,16,17}$ Berdasarkan hasil uji regresi logistik ganda diperoleh variabel yang dominan yang signifikan $(p=0,000)$ berpengaruh terhadap pemanfaatan pelayanan posyandu lanjut usia adalah jarak rumah dengan Puskesmas. ${ }^{18}$

Suatu penelitian selainnya menyatakan bahwa faktor-faktor yang berhubungan dengan keikutsertaan lansia dalam posyandu lansia adalah umur, pendidikan, pekerjaan, pendapatan, sumber daya kesehatan, fasilitas kesehatan, dukungan masyarakat dan kebijakan pemerintah. ${ }^{19}$ Pelayanan kesehatan di puskesmas ataupun rumah sakit akan dapat berpengaruh pada jumlah kunjungan pasien. Lebih lanjut dalam program lansia di Puskesmas Nanggulan ini dipengaruhi oleh faktor kepuasan pelayanan Puskesmas. Dimana dari pihak puskesmas sudah menerapkan program santun. Hal tersebut tidak sejalan dengan penelitian yang menyatakan dampak yang belum dicapai oleh puskemas yaitu realisasi cakupan pelayanan kesehatan lansia sebesar $70 \%$ dan ketersediaan fasilitas santun lansia. ${ }^{20}$

Disamping itu adanya dukungan dari pihak keluarga lansia yang memberikan waktu untuk lansia dan bersedia mengantarkan lansia mengikuti program lansia di puskesmas. 
Meskipun demikian terdapat kemungkinan adanya faktor penghambat yaitu kesulitan dalam berkomunikasi dengan lansia, dana swadaya yang belum mencukupi untuk setiap pertemuan dan kurangnya dukungan beberapa keluarga lansia. ${ }^{21}$ Dari analisa ini dapat dibuat inovasi upaya peningkatan kunjungan pelayanan lansia adalah dengan mengaturkan agenda untuk diadakan kegiatan program lansia di setiap dusun, dengan cara bergantian sesuai jadwal, kemudian menginformasikan kegiatan tersebut melalui tokoh masyarakat setempat atau pengurus dusun bahwa ada kegiatan program lansia dari puskesmas. Bentuk kegiatan yang demikian bisa dengan cara mengadakan program posyandu lansia di wilayah kerja Puskesmas Nanggulan Kulon Progo. Diharapkan hal ini dapat membantu meringankan pasien lansia yang jarak rumahnya jauh. Bentuk pelaksanaan program lansia di posyandu lansia yang diaktifkan kembali juga dapat digunakan sebagai solusi dari rendahnya cakupan kunjungan pasien lansia di Puskesmas Nanggulan Kabupaten Kulon Progo. Posyandu lansia adalah suatu wadah pelayanan kesehatan bersumber daya masyarakat (UKBM) untuk melayani penduduk lansia, yang proses pembentukan dan pelaksanaannya dilakukan oleh masyarakat Bersama Lembaga swadaya masyarakat (LSM), lintas sector pemerintah dan non-pemerintah, swasta, organisasi sosial dan lain-lain, dengan menitikberatkan pelayanan kesehatan pada upaya promotive dan preventif. ${ }^{23,24}$ Posyandu lansia harapannya dapat dilakukan di tempat yang berdekatan dengan wilayah rumah lansia di wilayah Puskesmas tersebut.

\section{DAFTAR PUSTAKA}

1. Buku Profil Kecamatan Nanggulan Tahun 2014. Kabupaten Kulon Progo.

2. Peraturan Menteri Kesehatan Republik Indonesia Nomor 25 Tahun 2016 Tentang Rencana Aksi Nasional Kesehatan Lanjut Usia Tahun 2016 2019.
Hal ini didukung dengan adanya kepuasan responden terhadap pelayanan yang sudah diberikan pihak Puskesmas Nanggulan, sehingga diperkirakan adanya inovasi pelaksanaan program yang demikian dapat didukung oleh masyarakat lansia di wilayah kerja Puskesmas Nanggulan. Kebijakan pelayanan kesehatan primer harus bersifat holistik dan komprehensif, terjangkau, dan dalam upaya meningkatkan kemandirian lansia dan keluarga serta didukung oleh peran kader. $^{25}$

\section{KESIMPULAN DAN SARAN}

Keikutsertaan dalam pogram lansia di Puskesmas Nanggulan Kulon Progo Yogyakarta dipengaruhi oleh kepuasan pelayanan dari pihak Puskesmas. Lansia dan atau keluarga lansia dalam hal ini memilih Puskesmas Nanggulan sebagai tempat pemeriksaan kesehatan namun meski demikian tidak berpengaruh terhadap keikutsertaan mereka pada program lansia karena adanya faktor akses atau jarak rumah dengan Puskesmas Nanggulan. Usaha untuk meningkatkan kunjungan lansia dapat dilakukan dengan inovasi mengadakan kegiatan program yang bertempat di kantor setiap dusun yang mana akan lebih memudahkan masyarakat lansia mendapatkan informasi dan menjangkau tempat pelaksanaan pelayanan kesehatan serta program lansia seperti senam sehat lansia juga cek kesehatan lansia di Puskesmas Nanggulan Kulon Progo.

(http://www.kesmas.kemkes.go.id/assets/ upload/dir_519d41d8cd98f00/files/PMKNo.-25-Tahun-2016-ttg-Rencana-AksiNasional-Kesehatan-Lanjut-Usia-Tahun2016-2019_867.pdf )

3. Undang-undang Republik Indonesia Nomor 36 Tahun 2009 Tentang Kesehatan. 
(http://www.depkes.go.id/resources/dow nload/general/UU\%20Nomor\%2036\%20 Tahun2\%20009\%20tentang\%20Kesehata n.pdf )

4. Standar Pelayanan Minimal Bidang Kesehatan di Provinsi dan Kabupaten/Kota. Kementrian Kesehatan. 2015.

https://www.slideshare.net/ssuser200d5e/ draft-standar-pelayanan-minimalkesehatan-2015)

5. Arikunto, S. Prosedur Penelitian: Suatu Pendekatan Praktik. Jakarta: PT Rineka Cipta. 2006.

6. Cresswell, John W. Research Design. Pendekatan Kualitatif, Kuantitatif, dan Mixed. Edisi Ketiga. ISBN: 978-6028764-84-1. Pustaka Pelajar, Yogyakarta. 2014.

7. Nazir, Moh. Metode Penelitian. ISBN: 979-450-173-5. Ghalia Indonesia, Pejaten Barat, Jakarta. 2003.

8. Sugiyono. Metode Penelitian Kombinasi (Mixed Methods). ISBN: 978-602-932806-6. Alfabeta, Bandung. 2014.

9. Kuntoro. Tehnik Sampling. Edisi Kedua. Surabaya: Airlangga University Press. 2010.

10. Profil Kesehatan Kabupaten Kulon Progo Tahun 2013. http://www.depkes.go.id/resources/downl oad/profil/PROFIL_KAB_KOTA_2012/ 3401_DIY_Kab_Kulon_Progo_2012.pdf )

11. Buku Profil Kecamatan Nanggulan Tahun 2014. Kabupaten Kulon Progo.

12. Maryati Heni, Fatoni A, Hexawan. Gambaran Faktor-Faktor yang Mempengaruhi Lansia Tidak Mengikuti Posyandu Lansia di Posyandu Dahlia Ngabar Desa Sumberteguh Kecamatan Kudu Kabupaten Jombang Tahun 2013. Skripsi. STIKES Pemkab Jombang. 2013.

(www.stikespemkabjombang.ac.id/ejurna 1/index.php/Juli.../4)

13. Ningsih R, Arneliwati, Widia Lestari. Factor-faktor yang Mempengaruhi Minat Lansia Mengunjungi Posyandu Lansia. JOM PSIK VOL.1 NO.2 Oktober 2014. 2014.

(https://media.neliti.com/media/publicati ons/183825-ID-faktor-faktor-yangmempengaruhi-minat-la.pdf)
14. Anita. Respons Lanjut Usia Terhadap Pelayanan Kesehatan Rawat Jalan di UPTD Panti Sosial Tresna Werhda Nirwana Puri Kalimantan Timur. 2014.

15. Henniwati. Faktor-faktor yang Mempengaruhi Pemanfaatan Pelayanan Posyandu Lanjut Usia Di Wilayah Kerja Puskesmas Kabupaten Aceh Timur. Tesis. Sekolah Pascasarjana Universitas Sumatera Utara. Medan. 2008. (http://repository.usu.ac.id/bitstream/han dle/123456789/6745/08E00905.pdf;jsessi onid=1962A51FBE4E08B60A28919245 3B7C7E?sequence $=1$ )

16. Peraturan Pemerintahan Republik Indonesia Nomor 43 Tahun 2004. Tentang Pelaksanaan Upaya Peningkatan Kesejahteraan Sosial Lanjut Usia. (https://www.google.co.id/searchab..8.38 .6913...0j0i131k1j0i3k1j0i22i30k1.0._1B w6bwztGk)

17. Keputusan Menteri Kesehatan Republik Indonesia No. 128/Menkes/SK/II/2004 Tentang Kebijakan Dasar Pusat Kesehatan Masyarakat.

18. Lavety, D Yanuar. Peran Puskesmas dalam Upaya Memberdayakan Lansia untuk Meningkatkan Kesehatan Lansia di Purwokwerto Selatan. Skripsi. Fakultas Ilmu Pendidikan Universitas Negeri Yogyakarta. 2016.

19. Purnawati, Nina. Faktor-faktor yang mempengaruhi kunjungan lansia dalam kegiatan Posyandu di Desa Plumbon Kecamatan Mojolaban Sukoharjo. Skripsi. Universitas Muhammadiyah Surakarta. 2014.

20. Silitonga, Febrilia Dewi C. Evaluasi Dampak Program Puskesmas Santun Usia Lanjut di Kota Semarang. Skripsi. Fakultas Ilmu Sosial dan Ilmu Politik Universitas Diponegoro. 2015. (https://media.neliti.com/media/publicati ons/135698-ID-evaluasi-dampakprogram-puskesmas-santun.pdf)

21. Sundari Sri dan Mentari P. Faktor-faktor yang berhubungan dengan keikutsertaan dalam Posyandu Lansia. Tugas Akhir. Akademik Kebidanan Ummi Khasanah; Bantul. 2012.

22. Wahono, Hesthi. Analisis Faktor-Faktor yang Mempengaruhi Pemanfaatan Posyandu Lansia di Gantungan Makamhaji. Skripsi. Fakultas Ilmu 
Kesehatan Muhammadiyah Surakarta. 2010.

(http://eprints.ums.ac.id/9520/1/J210080 010.pdf)

23. Keputusan Menteri Kesehatan Republik Indonesia Tentang Pedoman Pelaksanaan Promosi Kesehatan di Puskesmas. Nomor. 585/Menkes/SK/2007. (http://www.depkes.go.id/resources/dow nload/promosi-kesehatan/pedomanpelaksanaan-promosi-kesehatan-dipuskesmas.pdf)
24. Pusat Data dan Informasi Kementrian Kesehatan RI. Situasi dan Analisis Lanjut Usia. Infodatin 2016. 2016. (www.depkes.go.id/download.php?.../inf odatin/infodatin\%20lansia...)

25. Zulfitri, Reni. Analisis Kebijakan Pelayanan Kesehatan Primer dalam Manajemen Pelaksanaan Penyakit Kronis Lansia. Jurnal Kesehatan Masyarakat Andalas. p-ISSN 1978-3833 e-ISSN 2442-6725 10(1)52-58. 2015. (Jurnal.fkm.unand.ac.id/index.php/jkma/ article/view/163) 